\title{
The Current Status of General Health Education Curriculum in Technical Institutes and Universities in Taiwan
}

\author{
Su-Chang Chen \\ Department of Marketing and Logistics Management, National Penghu University, Penghu, Taiwan, China. \\ Email: csc@npu.edu.tw
}

Received April 13 ${ }^{\text {th }}, 2010$; revised May $14^{\text {th }}, 2010$; accepted June $1^{\text {st }}, 2010$.

\begin{abstract}
The purpose of this study is to understand the current status of the establishment of "general health education curriculum" by technical institutes and universities in Taiwan. A questionnaire survey method was used. A total of 75 questionnaires were sent and 41 were returned; the valid return rate was $54.7 \%$. The result showed that the courses on general health can be categorized into four groups: physiological, psychological, nutritional, and fitness health. Group the curriculum by academic fields, and the natural sciences are the course offered by most schools. Group the curriculum by subjects, and courses offered by non-medical institutes focused mostly on psychological and lifestyles (health psychology), while that of the medical-related institutes offer most curriculums in health management (health promotion, health-related physical fitness), health and exercise, medicine and lifestyles (healthcare and life) and nutrition.
\end{abstract}

Keywords: Health, General Health Education, General Technological Vocational Education, Technical Institutes and Universities

\section{Introduction}

General education in Taiwan started as "liberal education" in Tunghai University in 1956. General education became a part of university education in 1984 when the Ministry of Education circulated a memorandum to the schools. However, the Interpretation No. 380 by the Supreme Court in 1995 considered that the common courses in the universities had exceeded University Law, and was in disagreement with the purposes of the Constitution. The interpretation opened the turning point for the schools to re-plan the common and general curriculum in Taiwan $[1,2]$. In response to the difference in the period of time, the difference in social and cultural backgrounds, the philosophy and the objectives, each school should establish various curriculums in general education [3]. Lin considered that the characteristics of students from technical institutes and universities are different from that of general universities since the basic functions of an university is to carry human cultural responsibility into academic research, development and inheritance,

This paper is revised from 2006 General Education Conference, Tainan CUMT. The author would like to acknowledge the support of the National Science Council of Taiwan for the contract number of NSC 94-2516-S-346-001. while the nature of technical and vocational education is to take on the social construction in the use of professionalism and technology, research, development and innovation [4]. The aptitude of the students from technical institutes and universities should be considered when studying general technological and vocational education [5]. From the perspective of organization, Chen believed that if specialized courses are compared as line department, then general education is like the staff department; line and staff should be complementary to each other in order to accomplish the mission of the organization. The specialized education can satisfy the operating core, middle line and strategy apex of the organization, whereas general education provides technical structure and supporting staff services from a quality perspective to support the goal of professional subjects to cultivate the whole person. In another words, specialized and general curriculum should have a cooperative relationship [6].

Most of us spend our lifetime at the workplace; therefore, maintaining a safe working environment and a sound mind and body becomes very important issues [7, 8]. "Healthy" means a condition without diseases and that the body is at a comfortable physiological, psycho- 
logical, social, and spiritual state of health [7,9]. Since many epidemiological researches indicate that the cause of chronic diseases is related to unhealthy lifestyles, the engagement of health promotion activities can reduce the occurrence of diseases and death [10]. Thus, it is necessary to implant the students about health-related knowledge during school.

The nature of technical institutes and universities is focused on the workplace in the training of human resources, not on academic research; therefore, theoretically speaking, since every graduate from the technical institutes and universities will enter the work force, maintaining good health or paying attention to safety at work should be a basic skill for each student. The purpose of this study is to understand the current status of the establishment of general health education curriculum in technical institutes and universities in Taiwan, and to provide the findings to the education administration authority and every technical institute and universities as a reference.

\section{Literature Review}

\subsection{General Technological and Vocational Curriculum}

Wu defined general technological and vocational education as 'the 'professional development' combining specialized and generalized skills. Together with technological and vocational specialization as a base to conduct orientation in the nature, the society, the humanity, the technology and the religion to promote the overall sustainable development of cognitions, skills, and attitudes according to the individual's conditions, and thus to practice such skills in reality" [11]. Lee et al. pointed out that general education of university should be established with different contents according to the different periods of time, social and cultural background, school philosophy and objectives [3]. For example, Lee believed that the purpose of general education for military academies is to reflect the values of judging faithfulness and deceitfulness, obedience and disobedience, right and wrong, correctness and mistake, gains and losses, advantages and disadvantages, the fundamental and the incidental, and the state of urgency, by the students who received the basic education [12]. Sun deemed that the planning of the general education in teachers colleges should provide students a wider view to expand humanistic, social, cultural, scientific and philosophic perspective, and to cultivate knowledge integration, independent thinking, critical reflection, and lifelong learning abilities [13]. Focusing on the school's characteristics, Fooyin University has designed the "Healthy life" general curriculum; from paying close attention at health issues to foster its students to become a professional, sentimental, macroscopic viewed, and graceful healthcare professional [14].
$\mathrm{Yi}$ indicated that the nature of technological and vocation, the instructor's qualification and the quality of the student are the three predicaments faced by the technological and vocational education system in Taiwan when promoting general education [2]. Since the nature of the technological and vocational education system is career oriented, the mentality of the students usually emphasizes specialized subjects and neglects general curricula. If the philosophy of specializing general education and generalize special curricula cannot be blend in, the position of general education in technical institutes and universities will be more marginalized. Next is the dilemma of teachers' qualification. Since many technical institutes and universities are mostly restructured from junior colleges, the ability of the instructors from junior colleges teaching general education and managing the requirement of a general diversified curriculum is rather worrying. In order to accommodate current teaching expertise and teaching hours, schools usually resort to teacherbased mode in setting up the curricula; which makes them twice as difficult to achieve the goal of diversified learning. Last is the problem with the source of the students. Since most students in technical institutes and universities come from students with unsatisfactory junior academic performance that are forced to select junior college or senior vocational school, their abilities in basic subject are weaker; which means that the student's abilities in basic subjects should be considered when planning their curriculum.

\subsection{General Health Education Curriculum}

"Healthy" means a condition without diseases, and that the body is at a comfortable physiological, psychological, social, and spiritual state of health, therefore, physiological, psychological, social and spiritual aspect of health should be included [7,9]. In 1978, the WHO proposed the famous Alma-Ata Declaration that affirmed health as a fundamental human right, and the government is responsible to promote the health of its people through adequate activities. Chen and Lai included the four dimensions: self-responsibility, nutritional awareness, stress management, and physical fitness, into promoting a healthy lifestyle [15]. Walker, Sechrist and Pender defined healthy lifestyle promotion as: a multi-level spontaneous behavior and awareness of maintaining or promoting one's health, self-realization and self-satisfaction [16]. Health-promoting behaviors should include regular exercises, leisure activities, resting, adequate nutrition, stress-reduction activities, and the development of social support system.

According to the national nutrition investigation in 2000, $14.6 \%$ male and $15.8 \%$ female adults in Taiwan suffer obesity from an improper lifestyle, such as inadequate exercise. It is estimated that there are approximately 2.2 million adults who are excessively obese. 
Many medical reports point out that inadequate exercise complicated with obesity is the root of many chronic diseases such as hypertension, diabetes, and cardiovascular diseases [17]. In a long run, such a life style places a heavy influence on the health of the citizens. Promoting health education in technical institutes and universities and cultivating a healthy lifestyle has become the highest priority of current technological and vocational general education.

An investigation by Chen, Chang and Jing on 530 day and night school students from the Penghu Institute of Technology showed that interpersonal support ranked number one if ordered by average of each subentry in the health lifestyle; followed by self-realization, stress management, nutrition, and fitness. Health responsibility was ranked the lowest. The behavior for a healthy lifestyle has become a more common level [18]. From this, it should be realized that exercise, nutrition, health responsibility, health insurance and other health promotion issues are easily neglected by technical institutes and universities students. Therefore, it is necessary to require the students to pay attention to these issues in general health education curriculum; hopefully, the students' unhealthy lifestyles can be corrected through the curriculum and can be maintained until entrance of the workplace. Further, whether the technical institutes and universities pay attention to the teaching of general health education of the students should be further investigated.

\section{Method}

The questionnaire survey is used in this study. The questionnaire is constructed by the author. The contents included the fields of the schools' general curriculum and the status of general health education curriculum in the four-year technical institutes and universities.

The survey is sent to the director of General Education Division in 75 schools, which listed on the recruiting brochure for technical institutes and universities. A total of 41 surveys were returned after follow-up contact, and the valid return rate was $54.7 \%$. The returned surveys were processed and statistical analyzed.

There were 15 technical universities (36.5\%) and 26 technical institutes $(63.5 \%)$ was returned; among which, $10(24.4 \%)$ were public and $31(75.6 \%)$ were private, and 8 (19.5\%) has medical-related schools while 33 (80.5\%) does not.

\section{Results}

The general curriculum credit among 12 schools (34.3\%) of 35 technical universities and institutes ranked the highest, ranged 10 12; 7 schools (20\%) ranked second with more than 30 credits, probably listed the common subjects in the general curriculum. Usually, general curriculums should range between 8 to 16 credits in techni- cal institutes and universities. It shows in Table 1.

Classified by academic fields, 16 schools (39\%) focused most of the subjects in general health education on nature sciences; followed by 9 schools $(22 \%)$ that focused on social sciences; next were the 6 schools (14.6\%) that focused on life education and lastly, 4 schools on physical fitness and health field. The findings indicate that the two levels of general health education in physiological and psychological health are the mainstream. It shows in Table 2.

According to the investigation, general health education subjects can be categorized into physiological, psychological, nutritional, and fitness health. Psychological health includes health management, health promotion, medicine and lifestyles, drugs and lifestyles, and etc; psychological health includes medicine and life, heath and life, stress management, emotional management, psychology and lifestyles, healthy mind, and etc; food health includes diet and health, nutrition and lifestyles, food and health, and etc; physical health includes health and exercise, health-related physical fitness, traditional Chinese medicine and health preservation, Qigong and health preservation, leisure and sports, and etc.

The arrangements may be related to the teachers' structure; generally, teachers specialized in sports take charge

Table 1. The general health curriculum classified by credit

\begin{tabular}{lcc}
\hline \multicolumn{1}{c}{ Credit } & Number of Schools & Percentage \\
\hline Under 8 credits & 6 & $17.1 \%$ \\
$10-12$ credits & 12 & $34.3 \%$ \\
$14-16$ credits & 5 & $14.3 \%$ \\
$26-28$ credits & 5 & $14.3 \%$ \\
30 credits up & 7 & $20.0 \%$ \\
Total & 35 & \\
\hline
\end{tabular}

Table 2. The general health curriculum classified by academic fields

\begin{tabular}{lccc}
\hline Subject & Number of Schools & Percentage & Ranking \\
\hline Nature Sciences Field & 16 & $39.0 \%$ & 1 \\
Social Sciences Field & 9 & $22.0 \%$ & 2 \\
Life Education Field & 6 & $14.6 \%$ & 3 \\
Physical Fitness Field & 4 & $9.8 \%$ & 4 \\
Health Field & 4 & $9.8 \%$ & 4 \\
Humanism and Arts Field & 3 & $7.3 \%$ & 6 \\
Applied Science Field & 3 & $7.3 \%$ & 6 \\
\hline
\end{tabular}


of courses related to health and exercise; those who specialize in counseling and psychology teach courses related to psychology and lifestyle or stress management.

The most common courses in general health education is health management (health promotion) and psychology and lifestyles (healthy mind) which is offered by 21 schools $(51.6 \%)$; followed by health and exercise courses which is offered by 18 schools $(43.9 \%)$; then courses in medicine and lifestyles (medicine and life) offered by 15 schools (36.6\%); lastly, stress management (emotional management) and nutrition and health courses offered by 13 schools (31.7\%). It shows in Table 3.

In the general health education curriculum offered by non-healthcare-related schools, psychology and lifestyles (healthy mind) ranked the top with 19 schools (57.6\%), followed courses in health management (health promotion, health-related physical fitness) by 16 schools (48.5\%), next are the courses in health and exercise with 13 schools $(39.4 \%)$, then are the courses in medicine and lifestyles (medicine and life) and stress management (emotional management) with 10 schools $(30.3 \%)$, and lastly, health and lifestyles with 9 schools $(27.3 \%)$; the findings may be related to the instructors available in the type of the institutions. It shows in Table 4.

In the general health education curriculum offered by medical-related schools, courses in health management (health promotion, health-related physical fitness), health and exercise, medicine and lifestyles (medicine and life) and diet and health ranked highest with 5 schools $(62.5 \%)$.

The result is slightly different to that of non-medical schools where psychology and lifestyles (healthy mind) are not the most common courses, and diet and health, the subject ranked last in non-medical schools, was ranked first. It shows in Table 5.

\section{Conclusions and Recommendations}

\subsection{Conclusions}

The study concluded that:

1) It is necessary to implant the students about healthrelated knowledge during school. Promoting health education in technical institutes and universities and cultivating a healthy lifestyle has become the highest priority of current technological and vocational general education.

2) Each technical institutes and universities offers health-related general education.

3) General health education offered by the technical institutes and universities can be roughly categorized into physiology, psychology, diet and sports.

4) Categorized according to academic fields, the general health education focused mostly on natural sciences and social sciences.

Table 3. Curriculum in general health education offered by technical institutes and universities

\begin{tabular}{|c|c|c|c|}
\hline Subject & Number of Schools & Percentage & Ranking \\
\hline Health and Life & 12 & $29.3 \%$ & 7 \\
\hline Health Management, Health Promotion & 21 & $51.2 \%$ & 1 \\
\hline Health and Exercise, Health-related Physical Fitness & 18 & $43.9 \%$ & 3 \\
\hline Medicine and Lifestyles, Medicine and Life & 15 & $36.6 \%$ & 4 \\
\hline Traditional Chinese Medicine and Life Preservation, Qigong and Life Preservation & 2 & $4.9 \%$ & 11 \\
\hline Stress Management, Emotional Management & 13 & $31.7 \%$ & 5 \\
\hline Health Maintenance and Lifestyles, Prevention Medicine & 10 & $24.4 \%$ & 9 \\
\hline Food and Health & 12 & $29.3 \%$ & 7 \\
\hline Psychology and Lifestyle, Healthy Mind & 21 & $51.2 \%$ & 1 \\
\hline Drugs and Lifestyles & 1 & $2.4 \%$ & 13 \\
\hline Nutrition and Lifestyles & 8 & $19.5 \%$ & 10 \\
\hline Diet and Health & 13 & $31.7 \%$ & 5 \\
\hline Leisure Activities & 2 & $4.9 \%$ & 11 \\
\hline Exercise and Life Preservation & 1 & $2.4 \%$ & 13 \\
\hline
\end{tabular}


Table 4. Curriculum in general health education offered by non-healthcare-related schools

\begin{tabular}{|c|c|c|c|}
\hline Subject & Number of Schools & Percentage & Ranking \\
\hline Health and Life & 9 & $27.3 \%$ & 6 \\
\hline Health Management, Health Promotion, Health-related Physical Fitness & 16 & $48.5 \%$ & 2 \\
\hline Health and Exercise & 13 & $39.4 \%$ & 3 \\
\hline Medicine and Lifestyles, Medicine and Life & 10 & $30.3 \%$ & 4 \\
\hline Traditional Chinese Medicine and Life Preservation, Qigong and Life Preservation & 2 & $6.1 \%$ & 11 \\
\hline Stress Management, Emotional Management & 10 & $30.3 \%$ & 4 \\
\hline Health Maintenance and Lifestyles, Prevention Medicine & 7 & $21.2 \%$ & 9 \\
\hline Food and Health & 8 & $24.2 \%$ & 7 \\
\hline Psychology and Lifestyle, Healthy Mind & 19 & $57.6 \%$ & 1 \\
\hline Drugs and Lifestyles & 1 & $3.0 \%$ & 13 \\
\hline Nutrition and Lifestyles & 7 & $21.2 \%$ & 9 \\
\hline Diet and Health & 8 & $24.2 \%$ & 7 \\
\hline Leisure Activities & 2 & $6.1 \%$ & 11 \\
\hline Exercise and Life Preservation & 1 & $3.0 \%$ & 13 \\
\hline
\end{tabular}

Table 5. Curriculum in general health education offered by medical-related schools

\begin{tabular}{|c|c|c|c|}
\hline Subject & Number of Schools & Percentage & Ranking \\
\hline Health and Life & 3 & $37.5 \%$ & 6 \\
\hline Health Management, Health Promotion, Health-related Physical Fitness & 5 & $62.5 \%$ & 1 \\
\hline Health and Exercise & 5 & $62.5 \%$ & 1 \\
\hline Medicine and Lifestyles, Medicine and Life & 5 & $62.5 \%$ & 1 \\
\hline Stress Management, Emotional Management & 3 & $37.5 \%$ & 6 \\
\hline Health Maintenance and Lifestyles, Prevention Medicine & 3 & $37.5 \%$ & 6 \\
\hline Food and Health & 4 & $50.0 \%$ & 5 \\
\hline Psychology and Lifestyle, Healthy Mind & 2 & $25.0 \%$ & 9 \\
\hline Nutrition and Lifestyles & 1 & $12.5 \%$ & 10 \\
\hline Diet and Health & 5 & $62.5 \%$ & 1 \\
\hline
\end{tabular}

5) Courses in health management (health promotion), and psychology and lifestyles (healthy mind) are most common in general health education, followed by health and exercise (health-related physical fitness), and lastly, medicine and lifestyles (medicine and life). Courses in psychology and lifestyle (healthy mind) ranked top in non-medical schools, followed by courses in health and exercise. Courses in health management (health promo- tion, health-related physical fitness), health and exercise, medicine and lifestyles (medicine and life), and diet and health, are the most common curriculum offered in medical-related schools.

\subsection{Recommendations}

Due to the conclusions, the recommendation is proposed as follow: 
1) The nature of technical institutes and universities is focused on the workplace in the training of human resources, since every graduate from the vocational and technological college will enter the work force, maintaining good health or paying attention to safety at work should be a basic skill for each student. It is recommended the health administration authority to encourage the schools to offer more courses in general health curricula.

2) The returned surveys from 41 schools showed that the schools more or less offer general health-related curriculum. A further investigation may be needed to study the un-recovered portion of the surveys; to determine if the technical institutes and universities failed to return the survey because no courses were offered, or any other reasons.

3) The investigation for this study was on the subject of the course only. Further researches on the material used for each subject, how the student select courses, or effectiveness of the instruction are recommended.

4) A follow-up to see if the graduate has applied the skilled acquired from general health education in workplace is suggested for future studies.

\section{REFERENCES}

[1] J. Jue, "Some Reflections on General Education in Taiwan," General Education Quarterly, Vol. 9, No. 2, 2002, pp. 143-151.

[2] Z. Y. Yi, "The Dilemma and Strategy of General Education in the Junior Colleges Upgraded to Institute of Technology: Take Oriental Institute of Technology as an Example," Journal of Oriental Institute of Technology, No. 21, 2001, pp. 1-11.

[3] K. L. Lee, H. T. Tsai and C. C. Lo, "Curriculum Planning on General Education: A Case Study," General Education Quarterly, Vol. 7, No. 1, 2000, pp. 67-92.

[4] H. M. Tsao, "The Principle Foundation of Technological and Vocational Education," Yu-DA Research, No. 2, 2001, pp. 164-171.

[5] H. C. Lin, "The Study of Music Listening Textbook for General Education Curriculum in National Technical Institutes," Master Thesis of Department of Music, Soochow University, 2002.

[6] S. C. Chen, "A Workplace Oriented Planning Framework of Health General Education Teaching Material for
Non-Medical Students in Technical General Course-An Example for Subject of Health and Life," Fooyin General Education Yearly, No. 4, 2005, pp. 173-191.

[7] J. H. Xu, "Health Promotion and Health Promotion in Workplace," The Labor Safe Health Message, No. 48, 2001, pp. 2-4.

[8] S. C. Tung and C. Y. Yen, "The Current Statue of Health Promotion in Hsinchu Scientific Park," Health Promotion \& Health Education Journal, No. 20, 2000, pp. 93-102.

[9] C. R. Chen, "The Performance and Implement of Workplace Health Promotion," The Industrial Safety Environmental Protection Reports, No. 18, pp. 11-12, 2003.

[10] M. Y. Chen, C. C. Chou, S. H. Huang, M. C. Wang, S. C. Chiou and C. L. Chang, "Chinese Version Revised and Tested of Health Promotion Lifestyle Scale," Chang Gung Nursing, Vol. 8, No. 1, 1997, pp. 14-24.

[11] G. K. Wu, "The Theoretical Construction and the Study of Present Situation of General Education in Technological \& Vocational Education," Doctor Thesis of Department of Education, National Taiwan Normal University, 1999.

[12] D. M. Lee, "The Current Conditions of General Education of the Military College with Perspective," General Education Quarterly, Vol. 5, No. 4, 1998, pp. 1-21.

[13] C. L. Sun, "Exploring the Teaching Quality of General Education at Teachers College: An Evaluation Perspective," Journal of National Taipei Teachers College, Vol. 17, No. 1, 2004, pp. 329-354.

[14] S. C. Ho and P. C. Sung "The Teaching Result of Health and Life Implement," Fooyin General Education Yearly, No. 4, 2005, pp. 153-171.

[15] S. C. Chen and Y. H. Lai, "Pender Theories of Health Promotion," Chang Gung Nursing, Vol. 10, No. 4, 1999, pp. 55-61.

[16] S. N. Walker, K. R. Sechrist and N. J. Pender, "The Health Promoting Lifestyle Profile: Development and Psychometric Characteristics," Nursing Research, Vol. 36, No. 2, 1987, pp. 77-81.

[17] M. L. Lee, "Healthily Promote Policy and Outlook," $A$ New Era of Taiwanese Health Promotes Conference, 2001.

[18] S. C. Chen, F. Y. Chang and L. L. Jing, "Health Promoting Lifestyle for Technological Institute Students in OffTaiwan Islands," Hawaii International Conference on Social Science Conference, 2004. 